\title{
Reconstruction of a Central Full-Thickness Glenoid Defect Using Osteochondral Autograft Technique from the Ipsilateral Knee
}

\author{
Marius Junker ${ }^{1,2}$ (D) Jörn Kircher ${ }^{2}$
}

Received: 26 May 2020 / Accepted: 25 June 2020 / Published online: 30 August 2020

(C) The Author(s) 2020

\begin{abstract}
Background Osteochondral defects (OCDs) of the shoulder represent a typical clinical problem and are difficult to manage. OCDs of the upper extremity are less common than those of the lower extremity. The incidence is reported to be between $5-17 \%$ in which the humerus is affected more frequently than the glenoid. OCD is often accompanied with symptoms and may appear secondary to trauma, instability or prior operation. The problem of the lesions is the missing blood circulation which makes the healing impossible. The hazard of OCDs is the progression to osteoarthritis. In spite of the effectiveness of total shoulder arthroplasty it is not the first option for young and active patients. The therapy options of OCD depend on the size and localization of the defect.

Purpose The aim of this multimedia article is to reveal a therapy option for OCDs of the glenoid.

Methods In this case we present the reconstruction of a central full-thickness osteochondral glenoid defect with an osteochondral autograft from the ipsilateral knee which was withdrawn using the OATS-Technique (Arthrex, Naples, Florida) to address the chondral as well as the osseous pathology. To the best of our knowledge there has been no such procedure performed and described so far.

Results The procedure lead to proper restoration of the defect.

Conclusion The demonstrated technique can be used to perform the reconstruction of a full-thickness osteochondral glenoid defect.
\end{abstract}

Keywords Shoulder · Glenoid · Defect · Autograft

Acknowledgements Open Access funding provided by Projekt DEAL.

Funding None.

\section{Compliance with ethical standards}

Conflict of interest The authors declare that they have no conflict of interest.

Ethical standard statement This article does not contain any studies with human or animal subjects performed by the any of the authors.

Electronic supplementary material The online version of this article (https://doi.org/10.1007/s43465-020-00190-8) contains supplementary material, which is available to authorized users.

Marius Junker

Marius.Junker@friedrichsheim.de

1 Orthopedic University Hospital Friedrichsheim, Marienburgstraße 2, 60528 Frankfurt, Germany

2 Department of Shoulder and Elbow Surgery, ATOS Klinik Fleetinsel Hamburg, Hamburg, Germany
Informed consent For this type of study informed consent is not required.

Open Access This article is licensed under a Creative Commons Attribution 4.0 International License, which permits use, sharing, adaptation, distribution and reproduction in any medium or format, as long as you give appropriate credit to the original author(s) and the source, provide a link to the Creative Commons licence, and indicate if changes were made. The images or other third party material in this article are included in the article's Creative Commons licence, unless indicated otherwise in a credit line to the material. If material is not included in the article's Creative Commons licence and your intended use is not permitted by statutory regulation or exceeds the permitted use, you will need to obtain permission directly from the copyright holder. To view a copy of this licence, visit http://creativecommons.org/licenses/by/4.0/.

\section{References}

1. Arai, Y., Hara, K., Fujiwara, H., Minami, G., Nagakawa, S., \& Kubo, T. (2008). A new arthroscopic-assisted drilling method through the radius in a distal-to-proximal direction for osteochondritis dissecans of the elbow. Arthroscopy, 24, 237e1-4. 
2. Buchmann, S. (2012). Early clinical and structural results after autologous chondrocyte transplantation at the gleno-humeral joint. Journal of Shoulder and Elbow Surgery, 21(9), 1213-1221.

3. DePalma, A. A., \& Gruson, K. I. (2012). Management of cartilage defects in the shoulder. Curr Rev Musculoskelet Med, 5, 254-262.

4. Kircher, J. (2016). Knorpeltherapie in anderen GelenkenSchultergelenk. In J. A. Fritz \& P. Niemeyer (Eds.), Hrsg. Knorpel-therapie (pp. 242-247). Berlin: deGruyter.

5. Kircher, J., Patzer, T., Magosch, P., et al. (2009). Osteochondral autologous transplantation for the treatment of full-thickness cartilage defects of the shoulder: results at nine years. Journal of Bone and Joint Surgery (British Volume), 91, 499-503.

6. Millett, P. J., Huffard, B. H., Horan, M. P., Hawkins, R. J., \& Steadman, J. R. (2009). Outcomes of full-thickness articular cartilage injuries of the shoulder treated with microfracture. Arthroscopy, 25(8), 856-863.
7. Scheibel, M., Bartl, C., Magosch, P., et al. (2004). Osteochondral autologous transplantation for the treatment of full-thickness articular cartilage defects of the shoulder. Journal of Bone and Joint Surgery (British Volume), 86, 991-997.

8. Slabaugh, M. A., Frank, R. M., \& Cole, B. J. (2010). Resurfacing of isolated articular cartilage defects in the glenohumeral joint with microfracture: Surgical technique and case report. American Journal of Orthopedics (Belle Mead NJ), 39(7), 326-332.

Publisher's Note Springer Nature remains neutral with regard to jurisdictional claims in published maps and institutional affiliations. 